\title{
panic! affect contagion, in the mimesis and suggestion social field \\ ANNA GIBBS
}

\begin{abstract}
Sympathetic induction of emotions is displayed in the simplest and most unmistakable fashion by many, probably by all, of gregarious animals ... One of the clearest and commonest examples is the spread of fear and its flight-impulse among the members of a flock or herd. ${ }^{1}$
\end{abstract}

The characteristic of contagion is critical for the social responsiveness of any organism. ${ }^{2}$

The publication in 1989 of Panic Encyclopedia: The Definitive Guide to the Postmodern Scene probably marked the end of panic as a pervasive trope of contemporary cultural theory. ${ }^{3}$ The Encyclopedia posed the 'postmodern condition' as fragmentation: a 'dissolution of facts' and a proliferation of the knowledges of everyday life and cultural theory alike in disjoined fragments of story. This is a condition the form of the encyclopedia itself acts out, or compulsively repeats, even as it gestures towards a hypothetical totality of comprehensiveness and the possibility of order represented by the very idea of an alphabetically imposed sequence of entries. The emotional analogue of all this is conceived as a complex of mixed feelings composed of the 'ecstasy of catastrophe and the anxiety of fear'. ${ }^{4}$ Here the Encyclopedia attempts to link subjective experience to cultural analysis, but in so doing it may have failed to accurately diagnose either the macro or the micro levels of the social climate. It may also have posited an oversimplified view of the relationship between the micro realm of psychology and the macro level of the social as one of a kind of congruence in which the social is simply an amplification of the individual. What it does accurately intuit, however, is what is at stake in panic as a vector in the social field. This is an acknowledgment that truth, rationality and representation are no longer (if they ever were) sustainable as adequate 
terms in which to think either the social or the political. Serge Moscovici hinted as much when he observed, in 1986, that 'government by suggestion has replaced government by discussion'. ${ }^{5}$ But what exactly does this mean? Over the last fifteen years or so various cultural theorists have proffered analyses of mediatised political figures (Ronald Reagan, George W. Bush, John Howard) that — without necessarily using the term suggestion itself-attempt to map the work of affect in the political terrain. ${ }^{6}$ Now may be the moment to look more closely at just what this term might imply and what the nature of its relation to panic might be.

Recent renewed interest in suggestion has been given new impetus by the rediscovery of the work of nineteenth-century French sociologist Gabriel de Tarde. ${ }^{7}$ Tarde draws on the psychology of his day (concerned above all with sympathy, hypnotism and suggestion) and the nascent social psychology (which extended these concerns to the psychology of crowds) to elaborate a new theory of the social in which it appears as the actualisation of virtual potentials already present in individuals. For him, the phenomenon of hypnotic suggestion functions as the extreme instance which illuminates the ordinary state of social life (a point to which I will return). Like other writers of his time, Tarde gives a good deal of consideration to crowds as a site of affect contagion in which the tendency to panic exemplifies irrationality. ${ }^{8}$ The birth of publics — which Tarde was among the first to identify and describewould seem to augur a social life less prone to contagion and suggestion than that of the age of crowds, because, among other things, publics are believed to be more disembodied than crowds. ${ }^{9}$ But is this actually the case? A closer look at panic from a psychological perspective may provide a useful starting point in opening further exploration of this question.

According to some forms of contemporary psychoanalysis, the Encyclopedia might be said to get cause and effect (although it would probably be in denial, as they say, that it dealt in such terms) the wrong way round. Psychologically speaking, it is not fragmentation that causes panic, but anxiety escalating into panic that overwhelms the self and fragments it. Fragmentation in this sense means loss of psychic cohesion, loss of a sense of continuity (ongoing being in the world), and a collapse of the self into an overwhelming affect state in which any capacity for self-reflection and affect regulation disappears. Panic results from overwhelming affect on the loose and out of control. Diminished cognitive capacity for evaluation of alternatives means that agency is compromised. In contrast to terror, which is the most extreme form of fear and to which the typical behavioural responses are fight, flight or freeze, panic implies frenzied but pointless or self-defeating fight or flight. The outcome of this may be catastrophic and, because in panic the degree of fear needed to induce a thrill has been far exceeded, it's hard to see why it should be celebrated.

Panic represents an extreme level of arousal of what Silvan Tomkins's affect theory identifies as the discrete affect fear-terror. ${ }^{10}$ Probably the most contagious of all affects, like anger-rage, 
but unlike distress-anguish, fear-terror is an emergency affect. It is highly toxic to the organism when prolonged, as the phenomenon of 'voodoo death' demonstrates. Tomkins comments that panic 'may cost an individual his life not only if he freezes, but also if under its duress he surrenders all but the most primitive use of his capacities'. ${ }^{11}$ Neuroscientist Joseph LeDoux has since identified the means by which fear may be processed neurologically and flight or freeze responses immediately activated before cognitive evaluation of the danger can be made. ${ }^{12}$ The extreme toxicity of panic is one reason why the Encyclopedia's diagnosis is probably wrong: panic simply can't be sustained either at the individual or at the group level, where it means the splintering of the group into individuals driven entirely by their own needs ('every man for himself') and a loss of esprit de corps as when panic sets in among a crowd. In contrast to Tomkins, however, neuroscientist Jaap Panksepp sees what he calls 'the PANIC system' as a response to separation from care-givers, the purpose of which would be to produce feelings of distress and vocal crying that lead to action on the part of the child and/or parent to bring about reunion and the increased safety-emotional and physical-it provides. ${ }^{13}$ Over the long term, according to theorists of infant attachment, prolonged separation or the recurrent threat of it would lead to depressive anxiety and possibly to panic disorder; that is, to episodes of panic triggered by any perceived threat, real or imaginary.

Symptomatic of the lack of long-term viability of a panic state is that panic attacks have now become material for comedy-for example, the film Analyze This (1999), in which an anxious therapist is almost driven to the brink of terror when he takes on the analysis of a mobster whose panic attacks are interfering with his work. The same year saw the inaugural series of The Sopranos, in which mafioso Tony Soprano's panic attacks function as a darkly ironic device for the investigation of contemporary paranoia. For, as Patrick O'Donnell, cultural theorist of American paranoia, points out, if fear and panic are characteristic responses to the postmodern condition, then paranoia can be viewed as the reaction-formation par excellence to the schizophrenia of postmodern identity, economy and aesthetics. Visible in every aspect of late capitalist culture ... paranoia manifests itself as a mechanism that rearranges chaos into order, the contingent into the determined. ${ }^{14}$

As O'Donnell indicates, to prevent anxiety escalating into panic it is organised (or scripted, in Tomkins' terminology) into the relatively stable formations of paranoia-and, we might add, depression. Contrary to the Encyclopedia, it is the prevention of panic by the sustaining of anxiety that better characterises the contemporary scene. A similar diagnosis is rendered in numerous cultural analyses from Patricia Mellencamp's High Anxiety (1990), to Brian Massumi's edited collection The Politics of Everyday Fear (1993) and Kathleen Woodward's essay 'Statistical Panic'. ${ }^{15}$ Woodward suggests that there is a postmodern structure of feeling (rather then a totalising contemporary condition) characterised by an oscillation between 
boredom and the 'statistical panic' invoked by ubiquitous calculations of risk. ${ }^{16}$ As one of the characters in Don DeLillo's 1991 novel Mao II has it, we 'don't need catastrophes, necessarily. We only need reports and predictions and warnings'. ${ }^{17}$ Pervasive low-level anxiety has taken over from panic as the affect state that best corresponds to contemporary life in the West.

Anxiety, Jackie Orr argues, emerges as a (re)solution to the technocratic problem that arises with 'the systematic spiraling [sic] of panic prevention into panic production' as public campaigns about the need to control panic inevitably suggest that there may be good reason for it. ${ }^{18}$ It is in the Cold War period, Orr argues, that "panic theory emerges as a guide not only to the systematic control of its theoretical object but to its systematic creation'-or, I would suggest, the creation of anxiety as a means of facilitating control without losing it to panic, which is essentially out of control. ${ }^{19}$ Panic is affect with urgency but little discrimination. It is, in short, the figure of irrationality, produced as coterminous with affect contagion and mimetic communication. This is, of course, why it plays such a central role in the rhetoric of crowd theory as it attempts to understand modernity. Here panic comes to typify the irrationality of crowds, their impulsivity and their tendency-inevitably metaphorised as feminine-to descend into disorder and violence. ${ }^{20}$ Panic presents this paradox: on the one hand it shatters any esprit de corps because it produces a situation of 'each one for him/ herself', while on the other hand it represents the greatest moment of sensory receptivity of the human body to others-for in it, sympathetic or affective contagion is at its height. It binds, as Borch-Jakobsen puts it, 'in the mode of a non-bond'.

Affect contagion produces a mimetic relation between bodies and this, not the panic that stands in metonymically for it, is the real problem of crowds for their nineteenth-century theorists. The rise of panic discourse now may be symptomatic of the failure to fully account for the work of affect contagion, mimetic communication and suggestion in the social field. To begin this work we may need to turn back temporarily to a line of thinking all but abandoned in the wake of Freud, much as trauma theory in recent years turned back to Janet-not (at least not always) in rejection of psychoanalytic insights, but in a bid to reconfigure the intellectual landscape so as to wrest new possibilities from paths less taken. It is in this direction I now temporarily turn.

It is first of all affect that binds the crowd to a leader, uniting the mass of individual bodies into a force with its own purpose and direction. So, taking the automaton-like state of the subject of hypnosis as a model, one nineteenth-century crowd theorist, Gustav Le Bon, understood the crowd as 'mass without form'-but a mass which is nevertheless excitable because its members are like mediums entranced by suggestion and possessed by the will of the leader. ${ }^{21}$ It is the hypnotic subject that then becomes the nineteenth-century model for the 'non-subjectal' state of the individual in the crowd. ${ }^{22}$ Freud-wanting to distance 
psychoanalysis from the sorcery and charlatanism of suggestion and to make it a scienceattempted to transpose this account of crowd dynamics into his own libido-driven model of desire. ${ }^{23}$ In Group Psychology and the Analysis of the Ego, he largely displaces crowds in favour of institutions as the model of the group, but he argues that the masses seek their own subjugation out of love for the leader. This leader comes to stand in the position of ego ideala position formerly occupied by the father, for whom the leader psychically substitutes. The crowd members' love for the leader binds them not only to him but also to each other, along the 'fraternal' lines so well critiqued by Carol Pateman. ${ }^{24}$ Mikkel Borch-Jakobsen's brilliant but gender-blind critique of Freud points out that this 'fraternal' bond is contingent on the leader dispensing the 'illusion' that he [sic] loves all members of the group equally so that love for the leader binds aggression as well as narcissism. ${ }^{25}$

However, the bond between 'brothers' is not (only) libidinal but (also) identificatory, implying that each has internalised something of the other and is open to transformation after the model of the other. ${ }^{26}$ Identification, then, is essentially mimetic and may therefore generate considerable ambivalence. To qualify a bond as identificatory would seem to raise the complications of the possibly more complex forms taken by identification, some of which are hostile to its object, or which bind it to an object hostile to them. This can be seen in cannibalistic incorporation, where the subject aims to consume the object and take its place, ${ }^{27}$ or melancholic identification, ${ }^{28}$ where identification means attachment to a phantasmagorical object but cannot be given up. These problems are not addressed by BorchJakobsen. René Girard, however, has analysed the structural rivalry between 'brothers' that he concludes will inevitably be produced as a result of the convergence of desire on the one object. ${ }^{29}$ But for his part, Freud imagines that panic, when it occurs, will be precipitated by the loss of a leader who makes possible the "brothers' identification with each other: for him, the loss of the leader represents the decapitation of the body politic. Panksepp's analysis of panic as a response to separation from a parent seems to suggest an attachment metaphor for crowd behaviour. This poses similar problems to those presented by Freud's theory, since attachment problems with a parent figure may actually strengthen bonds between siblings, who must fend for themselves, and in any case the forms taken by attachment (especially to unreliable attachment figures) may be many, complex and highly ambivalent.

If it is the leader who will ultimately confer form on the formlessness of the crowd, ${ }^{30}$ the question of the nature of his or-perhaps especially-her control remains open. So too does the question of the distribution of agency in the crowd as a mimetic field. Is it the leader who dominates (suggestion) or the members of the crowd who willingly cede their putative autonomy to the leader (imitation)? Suggestion and imitation designate the constant poles between which agency in the crowd, as in other mimetic phenomena, will be seen to fluctuate. ${ }^{31}$ To speak of mimetic communication is to bring about, theoretically speaking, 
the return of the repressed in the form of the nineteenth-century corporeal unconscious, which had hitherto been a prominent feature of medical and philosophical discourses, but which Freud's work makes a concerted attempt to replace with the dynamic unconscious. ${ }^{32}$

The corporeal unconscious is animated by sympathy, a putative affinity between certain things_-including bodies and organs_-which makes them liable not only to be similarly affected by the same influence, but more especially to affect or influence one another. Sympathy is a concept with a long history in Western literary, philosophical and medical discourses. Foucault cites sympathy as being the most important of four forms of resemblance that organised, made possible and represented knowledge until the end of the sixteenth century. ${ }^{33}$ But in fact it persisted well into the nineteenth century, surviving in the fin de siècle French psychophysical theories of Ribot, Binet, Richet and many others who all drew on it to account for 'automatism' and suggestibility under hypnosis. Bernheim's description of suggestibility corresponds closely to what Ribot and Bergson both termed 'sympathy', that is, a mimetic relationship to others. The idea that it is corporeal mimesis (sympathy) that governs the body's automatisms begins to disappear as the dynamic unconscious gains greater attention. But what is arguably lost as hypnosis is superseded in psychoanalytic theory by transference, is a theory of the direct body-to-body transmission of both affects and the attitudes and ideas for which affect may, under certain conditions, become a carrier. ${ }^{34}$ With this loss, one potential way of accounting for the role of the non-rational in social and political processes is also lost. It is in this context that the idea of suggestibility might most usefully be re-examined, and here the work of Tarde is indispensable.

Sympathy, of which affect contagion is a major component, probably forms the corporeal basis of suggestibility. ${ }^{35}$ Although he is frequently accused of a faddish fascination with hypnotic automatism, Tarde sees it simply as an extreme instance of the automatism of subjectivity itself. ${ }^{36}$ Subjectivity, for him, is a centre of action that receives and transmits movements: it corresponds to senso-motorial memory. ${ }^{37}$ It is suggestion-which will reappear as the 'mimetic capacity' in the work of Benjamin and Adorno-that gives rise to imitation. Tarde sees this not as the production of second-rate copies, as the Platonic tradition in Western thought often does, but as memory in the form of habit, what we would now call procedural memory-or, more broadly, semantic memory. It is not simply cognitive, but involves nerves, muscles and affects. Imitation is 'suggested', then, both by the force of habit (the force of the past) and, more immediately, by the force of the sympathy that is the response to what is suggested by other bodies. Moreover, imitation has an exponential force, since:

this very will to imitate has been handed down through imitation. Before imitating the act of another we begin by feeling the need from which this act proceeds, and we feel it precisely as we do only because it has been suggested to us. ${ }^{38}$ 
The social state, then, is like a dream in which one seems to have control, but in which attitudes and courses of action that seem original and spontaneous are in fact the result of suggestion, not necessarily of individuals, but of environments. For Tarde, cities are the preeminent environments 'rich in suggestion'. 39

Imitation is a necessary process fundamental to social continuity and stability: it is the means by which novel inventions are taken up and formed into habit, custom and fashion as modes of social aggregation. Imitation, as Tarde conceives it, represents the conservation of the past and the preservation of a social bond. But it is not democratic in character. It is always suggested by prestige: it flows along hierarchical lines of force from the centre to margins, city to provinces, and from the nobility to the lower social orders. ${ }^{40}$ The rise of mass media (during Tarde's lifetime, this meant the press) begins to render publics more significant than crowds both in reality and in Tarde's work; Tarde comes to see imitation as a process that is lateral and sometimes mutual as well as hierarchical. ${ }^{41}$ While it is still produced by prestige, prestige doesn't pre-exist its conferral by the other. ${ }^{42}$ Suggestibility, then, means the according of prestige, power and superiority to the other: it is this action on our part that makes them desirable. ${ }^{43}$

For Tarde, what Le Bon diagnoses in 1895 as the 'era of crowds' already belongs to the past. ${ }^{44}$ He sees that while crowds are incapable of extension beyond a certain point, a public, the 'social group of the future', is indefinitely extensible thanks to printing, railways, the telegraph and, above all, that 'formidable telephone', the press. ${ }^{45}$ Tarde clearly predicates the suggestibility of publics on the relationship between bodies: in the first place on the human sensitivity to the gaze of others (especially in the density of urban life). This develops into sensitivity to the mere thought of this gaze and the attention that accompanies it. Similarly, the susceptibility to the voice of authority sensitises the reader to the voice of the text, and even to the imagined authority of other readers, whether that authority means the weight of numbers or the selectivity of an elite. ${ }^{46}$ The suggestibility of publics is, finally, a kind of 'contagion without contact', ${ }^{47}$ but Tarde seems to struggle to find a vocabulary to talk about the kind of influence exerted at a distance. He refers to it as 'ideal', speaks of the 'mental cohesion' of publics, and finally refers to it as 'interspiritual'. But he does not, as Borch argues, detach it altogether from suggestion. While I think Borch is right about Tarde's concern with the potential volatility of publics, such that they may always potentially form crowds, I do not think that suggestion in Tarde is tied to the idea of a leader (like an orator in a crowd) but rather that his work opens the idea that suggestion may be mediated in ways that escape the intentions of human operators. Like Sighele, his Italian contemporary, Tarde understands the kind of mediation at work in textuality. He cites Sighele writing of Robespierre's fascination with Rousseau, whom he read repeatedly, such that Robespierre becomes the 'succubus' to Rousseau's 'incubus', adding that the influence of Rousseau in person would have been 
doubtful. ${ }^{48}$ The medium of print may amplify any one of a number of qualities of the writer to different effects, ${ }^{49}$ and this separation of qualities tends to mutualise influence. Moreover, the qualities that make a person influential are not necessarily the ones that fascinate in a text: 'in these it is intellectual or imaginative superiority that is above all operative; in [the former] it is decisiveness, even if brutal, conviction, even if fanatical, and pride, even if mad, that are contagious'. ${ }^{50}$

Perhaps the other most important characteristic of publics (as opposed to crowds) for Tarde is their degree of self-consciousness of themselves as a public which may militate against suggestibility. ${ }^{51}$ The tendency of individuals to belong to more than one public simultaneously will make publics less prey to panic than crowds, though this will tend to produce a media milieu in which multiple concerns create a certain incoherence. ${ }^{52}$ Michael Warner, a contemporary theorist of publics, argues that dominant conceptions of 'the human' privilege and depend on an idea of the private reader as rational and critical ${ }^{53}$ and that this restricts our idea of their agency. ${ }^{54}$ Tarde's view of reading as a locus of suggestion evinces a view of it which is less disembodied, and less rational, than the view described by Warner. Tarde emphasises the irrationality of publics, provoked and amplified by the press, as it creates a 'fuss' about something. ${ }^{55}$ To analyse this fuss-making as 'moral panic' is to treat it primarily as a discursive and textual phenomenon, but Tarde's analysis of publics as susceptible to suggestion takes more fully into account the affective dimension of media engagement, and he does not necessarily see panic as the most important affective state created by media 'fuss'.

Equally significant for Tarde is the creation of fads which often involve the pleasures of consumption of luxury goods. The newspaper-via the power of repetition rather than by rational argument or even by rhetoric_-succeeds in making the reader 'hallucinate'. ${ }^{56}$ If Tarde sees publics as 'less extremist than crowds, less despotic or less dogmatic', he also believes that their despotism or dogmatism will be 'far more tenacious and chronic'. ${ }^{57}$ The most cursory consideration of the role of opinion polls in contemporary Western politics would seem to confirm this. But Tarde's interest in fads rather than panics should alert us to the need to consider an affect dynamics of publics and media in which the specific motivational force of each of the affects is taken fully into consideration. Can we simply assume that fearterror is a stronger motivational force than interest-excitement or that 'negative' affects are more compelling than 'positive' ones? There can be no answer to this question which does not take into account the particular environments to which these affects may be responding, nor the culturally specific ways in which affects are made to register in bodies and to perform the cultural work of producing relation and meaning. Both fear (self-preservation) and interest (novelty-seeking) would seem to be equally critical in human evolution, although fear arguably plays a greater part in the motivation of at least some animal species. In short, however, I would envision the development of what Virginia Nightingale calls a 'media psychology'. ${ }^{58}$ 
In my view, this would mean borrowing from Silvan Tomkins's culturally specific theory of affect scripting and developing other theories more appropriate for specific cultural groups, but drawing as well on neo-Deleuzian affect theories which in turn draw on Spinoza, but also on Leibniz for a particular understanding of the nature of the social. (Massumi's work would be the outstanding example of this kind of approach.) For, if Tomkins's work seems likely to open a more nuanced analysis of particular instances than most neo-Deleuzian analyses, the latter would seem to provide a more complex understanding of the relationship between the individual and the social than was available to Tomkins, and it is one better suited to the working of mediated social environments. I will return to the question of psychology by way of conclusion, but I turn now to Tarde's view of the social.

Tarde's neo-Leibnizian monadology conceives the social as what abstracts from individuals, or realises what is virtual in them, somewhat as a text realises what is virtual in an authorthe boundaries between individual and social are in constant negotiation such that the individual can never be a given. ${ }^{59}$ The individual, then, is not a microcosm of the social, but, as Lazzarato explains, 'the whole cosmos conquered and absorbed by a single being'. ${ }^{60}$ What this potentially produces is a relational thought that privileges the analysis of communication and flow over the analysis of the subjects and objects produced within it. Moreover, in this perspective acquisition and appropriation, having rather than being, are the terms that best characterise monads' ways of growing; in his commentary on Tarde, Deleuze explicitly links this to capitalism. ${ }^{61}$ This would seem to present an image of the social very suited to the analysis of the 'networked individualism' characterising the media environments described by Castells. ${ }^{62}$ In these environments data-mining has become the new resource boom. It produces information essential to exploiting Web 2.3's capacity to track what is being searched for and talked about on the internet and to connect it with advertisements targeting mobile phones at specific times and places, ${ }^{63}$ and particular affectively driven social networking sites-which thrive on the desire for connection, influence and prestige. These sites have become the means by which people now market themselves to the world, in response to the creation of the means-and thus the desire-to do so. They are the locus par excellence of imitation which imagines itself to be original. The corporations that own the sites also own, and can trade for profit, the data that users generate. Again Tarde is prescient: he looked towards the possibility of channelling, monitoring and managing the forms of imitation and contagion that he observed and theorised'. ${ }^{64}$ Perhaps it should be no surprise, then, that his writings, although outflanked in sociology by Durkheim, were taken up in the United States by American social influence or 'diffusion of innovations' theory. ${ }^{65}$ Moscovici comments of this that it has 'systematized and vindicated the use of collective suggestion (or propaganda, to call it by its rightful name) as a substitute to rhetoric for influencing public opinion' ${ }^{6}{ }^{6}$ Meanwhile, however, Adorno had already clearly identified the problem of 'effects research' that focused on the suggestibility of audiences. Such research at once implied that this 
suggestibility was where the problem lay and at the same time functioned as an instruction manual for advertisers and marketers, while ignoring the 'aims and practices of radio producers and the social and political structures within which radio is deployed' ${ }^{67}$

This suggests the need for a view in which communication is thought of as a complex system, since it is, as Stiegler puts it, 'the articulation between the nervous, technical, and social systems which constitute the total human fact'. ${ }^{68}$ Moreover, because we act 'in concert' with technology, media and things, 'technology and the practical use to which we put technology always exceeds the intentional structures that we build into it'. ${ }^{69}$ This is not to say that the agency of technology is either the same as human agency or entirely independent of it. ${ }^{70}$ The idea of agency is also now complicated by analyses of conversational entrainment that suggest that listeners as well as speakers take the lead in the sequences of movement that accompany and envelop speech. ${ }^{71}$ Suggestion is not the sole purview of government, nor even simply of advertising and marketing; it now forms part of a complex system in which multiple attractors exist and where quantitative differences can give rise to qualitative ones.

This being the case, why use the term suggestion at all? There are a number of reasons. To do so signals a certain set of genealogical relations linking nineteenth-century crowd theory to contemporary affect theory as it attempts to understand the non-rational element at play in the political, and the retraversal of this terrain may enable us to get a better grip on the tools to hand. ${ }^{72}$ Further, as Lazzarato indicates, power might be conceived-after Tarde and Foucault - as a force operating on others not so much to destroy them as to solicit, incite or 'suggest' courses of action. ${ }^{73}$ (For Tarde, this force is primarily affective and energetic.) Finally, because hypnosis has functioned as the main site of Western investigations of suggestion, suggestion re-opens the issue of trance in contemporary Western societies in ways that may be productive; in part because they destabilise the image of rationality on which Western thought depends and in part because they raise the question of how to create spaces of invention (the term Tarde opposes to imitation, though as he elaborates it the relationship between them is more complex than this might imply) in the face of suggestion.

In the first instance, to speak of suggestion raises the question of whether the 'distraction' of contemporary life-television, the freeway, the shopping mall ${ }^{74}$ — actually constitutes a contemporary form of trance? Could it be that the pervasiveness of media, marketing and so on in everyday life effaces the boundary that usually demarcates the time and place of trance as ritually or therapeutically induced? ${ }^{75}$ Julian Jaynes, writing brilliantly and eccentrically in 1976, sees trance states as a reactivation of the 'neural patterning' associated with a stage in human development before the invention of consciousness. ${ }^{76}$ Jaynes sees the 'bicameral paradigm' as comprising 'collective cognitive imperative, induction, trance, and archaic authorization', ${ }^{77}$ so for him neither trance-nor mimesis—originate in affect contagion or sympathy. He argues, rather, that trance and various forms of everyday distraction are quite distinctly different phenomena. What Jaynes could not have foreseen is the way in 
which the neurological dimension of the sympathetic response is beginning to be illuminated by the discovery of mirror neurons, and that of affect by the discovery of neuropeptides, ${ }^{78}$ so that today many would want to account for hypnosis in terms of affective attunement between operators and subjects. ${ }^{79}$ But the issue is also complicated because attempts to define hypnosis in terms that would satisfy the criteria of scientific method produce only artefacts. ${ }^{80}$ Western medicine tends to view trance phenomena along the same lines it considers the placebo effectas somehow 'not real', as opposed to the 'reality' of the action of drugs. ${ }^{81}$ Nevertheless, it does seem possible (to me, anyway) that distraction and trance are both forms of dissociation which are not simply different in terms of degree, but which are shaped according to social norms and the management of experts who administer them. As Jaynes himself points out, even hypnosis narrowly defined changes in relation to changing social expectations and preconceptions. ${ }^{82}$ Thus, while the 'distraction' characteristic of much contemporary life would seem to run counter to the narrowing of the focus of attention that usually forms part of hypnotic induction, it may be possible to argue that induction has simply become less ritualised, and that repetition —of political statements (say it often enough and it becomes as if true), of advertising, of news-has now become the main technique of induction.

While Tarde understands the routines of everyday life as the paralysis of belief and desire in habit, he also sees such routines as necessary for social and cultural continuity, and not something with which it would be either desirable or possible to dispense. They are the means by which culture can serve as 'a storehouse of crucial replicative information'. ${ }^{83}$ Jaynes, in keeping with his narrower definition of trance, sees it rather as a source of extraordinary power giving rise to the ability to do things which otherwise could not be done-such as undergoing surgery without anaesthesia. More importantly, it is a source of authorisation contributing to the generation of religion, poetry and music. In any case, to consider the present in terms of mimesis and the suggestion-imitation couple comprising it is to challenge the Western discourse of human 'progress', which sees the West as representing the most highly developed form of the human-the thinking, rational head of the inarticulate body. ${ }^{84}$ It might also be to understand that cultures that view the world in terms of animism and sorcery may be in a privileged position when it comes to understanding mimesis (mimetic communication) as modern magic. If it seems evident that advertising, marketing and public relations are forms of sorcery, so too capitalism more broadly can be thought of in these terms. ${ }^{85}$

More immediately, mimesis as suggestion-imitation enables thought about the non-rational dimension of contemporary Western politics, particularly as this involves the nature of belief. ${ }^{86}$ It is not simply, as Brian Massumi's recent work suggests, that a politics of belief grounded in truth has been superseded by a politics of affect. ${ }^{87}$ Rather, affect describes the means by which belief is created mimetically in the body of the public. 'Belief is finally the affective force of thought. ${ }^{\prime 88}$ Created only in the performative process of avowal, belief is dependent both on the way we inhabit language and what language does to us as we interiorise 
it. ${ }^{89}$ Belief depends on linking language with the somatic dispositions that produce it as an affective reality. Moreover, as Bourdieu writes,

Every social order systematically takes advantage of the disposition of the body and language to function as depositories of deferred thoughts that can be triggered off at a distance in space and time by the simple effort of re-placing the body in an overall posture which recalls the associated thoughts and feelings, in one of the inductive states of the body, which, as actors know, give rise to states of minds..$^{90}$

This is because the 'body believes in what it plays at: it weeps if it mimes grief'. ${ }^{91}$ And this in turn is what enables the creation of what Massumi has termed 'affective facts'. ${ }^{92}$ The example he gives is the affective reality of the fear created by the threat of something that hasn't yet happened: the 'threat that does not materialize is not false', but simply deferred. It could always happen, so the fear it generates can never be abolished by being proved groundless.

In this respect, I think, images—and especially the way they are used in news reportageplay a very particular part in the creation of affective facts. Massumi's own example of the supposed weapons of mass destruction (WMD) in Iraq makes clear why this might be. It seems that people generally have difficulty in remembering negation-especially when they are distracted-so that, if something is wrongly asserted and then later corrected, the correction often fails to register. Images of silos said to contain WMD not only accompanied news reports in which some experts were critical of what was being claimed about the existence of such weapons, but also accompanied some reports in which it was later admitted that the belief in their existence had been proven wrong. Today, however, it seems testimony to the power of the adage that 'seeing is believing' that as many as thirty per cent of Americans still believe Iraq had WMD. ${ }^{93}$ This is one reason why it seems to me that televisual images especially may function as a form of suggestion. What is perhaps more telling is that verbal correction of false information seems to count as repetition that reinforces the original information. At least, this seems to be the case when levels of scepticism are low. ${ }^{94}$ Images have a facticity that may continue to provoke anxiety in the face of better knowledge.

While Blackman argues the need to rethink suggestion as a way of reintroducing the psychological into considerations of the social, I would suggest this cannot be the psychology of old, but must instead be one that takes into account not only the intersubjective nature of human psychic life but also its reconfiguration in relation to nonhuman actors which may escape the intentions of their human operators-most importantly, of course, media. The experience of the crowd is still sought after: you go to the Big Day Out (a rock concert) 'not for the music, but to be part of a crowd', as one participant writes. ${ }^{95}$ But this experience is now augmented and amplified by large screens at concerts and sporting events, and images of the event are also relayed to other public sites. The media, which in some ways replaces crowds with publics, is now also used in the services of crowd formation, in the creation 
of organised public events. ${ }^{96}$ As Australians prepared for the Prime Minister's apology on behalf of the nation to the Stolen Generations, large screens were promised to appear in public places, not just in anticipation of crowds but to draw them. The screens would act to make the occasion a public event, certainly, but more importantly, would make it a transformative ritual, necessarily involving broadcast to remote publics as well as the creation of 'liveness' - a public here and now, without which there might be symbolism but no ritual.

The importance of ritual lies in its relation to the non-rational dimension of human social life and points to what Isabelle Stengers describes as the power of magic. ${ }^{97}$ When magic is conjured by collective ritual, the 'I' of the subject is not overwhelmed by affect of the crowd but instead something is made present which transforms the people's relation to the 'I', to psychology and to habit. ${ }^{98}$ Perhaps the transformation of people's relation to all that is at stake in the 'I' brought about by the apology will be in some ways transient. Even so, it may generate sufficient energy to aim, as Alfred Gell wrote of magic in general, to set 'an ideal standard, not to be approached in reality, towards which practical technical action can nonetheless be oriented'. ${ }^{99}$ In this case, such action would surely include compensationwhich itself is a symbolic gesture of reparation, since nothing could ever truly compensate for the wrong that has been done to indigenous people. But it is not 'merely' symbolic, because were it to happen, it would stand as real evidence of the power of a certain contemporary magic to transform the nature of non-indigenous Australians' stake in a particular 'I' and its attendant privileges, including financial. For finally it may be possible to envisage that these could, ideally, be given up.

Thus magic involves mimesis beyond the imitation-suggestion couple, mimesis as a movement that exceeds the subject. Not for nothing does Gell cite the child who 'asserts that he is an aeroplane (with arms extended, and appropriate sound effects and swooping movements)' as the prototype of magical play. ${ }^{100}$ Magic of this kind may, perhaps, be an antidote to contemporary anxiety disorder and the disaffection and disengagement it creates across the political field

ANNA GIBBS teaches writing in the School of Communication Arts at the University of Western Sydney, where she is also a member of the Writing and Society Research Group. She is currently completing an ARC funded research project, 'The Power of the Image', with Virginia Nightingale, investigating young people's affective responses to what they identify as disturbing images in all forms of media. She has also worked with affect theory as a clinical psychotherapist, and is working on a book on mimesis as mimetic communication. 
Early versions of sections of this work were presented at the Psychoanalysis and Culture conference, Rutgers University 2004, and the Ubiquitous Media: Asian Transformations conference, University of Tokyo, July 2007; papers presented to the Decolonizing Affect Theory conference, University of British Columbia, June 2006 and the Theorising Affect conference, Durham University, January 2007 attempted to elaborate the concept of mimesis sketched here. My thanks to Lisa Blackman, who chaired my session in Tokyo and also generously shared her own ideas with me over the course of that conference and the one in Durham at which she also gave papers, and to my Sydney colleagues Jennifer Biddle, Jill Bennett and Maria Angel for many wonderful and wide-ranging discussions of affective politics. And thanks as well to Katrina Schlunke for her help with the final edit.

1. William McDougall, An Introduction to Social Psychology, p. 79. n. 39. 16th edn, Methuen, London, 1921.

2. Silvan S. Tomkins, Affect, Imagery and Consciousness, vol. 1, The Positive Affects, Springer, New York, 1962, p. 296

3. Arthur Kroker, Marilouise Kroker, David Cook, Panic Encyclopedia: The Definitive Guide to the Postmodern Scene, St Martin's Press, New York, 1989

4. Kroker et al., p. 15

5. Serge Moscovici, 'The Discovery of the Masses', in Carl F. Graumann and Serge Moscovicii. (eds), Changing Conceptions of Crowd Mind and Behaviour Springer-Verlag, New York, Berlin, Heidelberg and Tokyo, 1986, p. 15.

6. Brian Massumi, 'Everywhere You Want To Be: Introduction to Fear', in Brian Massumi (ed.), The Politics of Everyday Fear, University of Minnesota Press, Minneapolis, 1993; Anna Gibbs, 'Pauline Hanson and the Epidemiology of Affect', 2001 $<$ http://www.lib.latrobe.edu.au/AHR/archive/ Issue-November-2001/gibbs.html>; Jenny Edbauer, 'Executive Overspill: Affective Bodies, Intensity and Bush-in-Relation', Postmodern Culture, vol. 15, no. 1, 2004; Maria Angel and Anna Gibbs, 'Media, Affect and the Face: Biomediation and the Political Scene', Southern Review: Communication, Politics and Culture, vol. 38, no. 3, 2005, pp. 24-39.

7. See, for example, essays in the recent issue of Economy and Society devoted to Tarde, vol. 36, no. 4, 2007, pp. 549-73.

8. See, for example, Gabriel Tarde, Lopinion et la foule, p. 30.

9. For example, Michael Warner, Publics and Counterpublics, Zone Books, New York, 2002; Jeffrey T. Schnapp, 'The Mass Panorama', Modernism/ modernity vol. 9, no. 2, 2002, pp. 243-81.
10. Silvan S. Tomkins, Affect, Imagery, Consciousness, vol. 2, The Negative Affects, Springer, New York 1965, pp. 10-11.

11. Tomkins, p. 10.

12. Joseph LeDoux, Emotional Brain: The Mysterious Underpinnings of Emotional Life, Simon and Schuster, New York, 1996.

13. Jaap Panksepp, Affective Neuroscience, Oxford University Press, New York, 1998. This is because he views PANIC as one distinct subcortical operating system and FEAR as another.

14. Patrick O'Donnell, Latent Destinies: Cultural Paranoia and Contemporary US Narrative, Duke University Press, Durham, 2000. O’Donnell views contemporary American paranoia as the internalisation at multiple sites ('Oklahoma City, Waco, Ruby Ridge, Bosnia, the White House, the United Nations'and so on) of Cold War paranoia.

15. Patricia Mellencamp, High Anxiety, Indiana University Press, Bloomington and Indianapolis, 1990; Brian Massumi (ed.), The Politics of Everyday Fear, University of Minnesota Press, Minneapolis and London, 1993; and Kathleen Woodward, 'Statistical Panic', Differences, vol. 11, no. 2, 1999 , pp.180-1.

16. Woodward, p. 180

17. Don DeLillo, Mao II, Vintage, New York, 1991, p. 72 .

18. Jackie Orr, Panic Diaries: A Genealogy of Panic Disorder, Duke University Press, Durham and London, 2006.

19. Orr, p. 132

20. Erika Apfelbaum and G. R. McGuires, 'Models of Suggestive Influence and the Disqualification of the Social Crowd', in Graumann and Moscovici (eds), Changing Conceptions of Crowd Mind and Behaviour. 
21. Gustave LeBon, The Crowd. A Study of the Popular Mind, trans. anonymous, Viking, New York, 1960, p. 14

22. Mikkel Borch-Jacobsen, The Freudian Subject, trans. Catherine Porter, Stanford University Press, Stanford, 1988, p. 139

23. This is, of course, also Borch-Jakobsen's reading.

24. Carol Pateman, The Sexual Contract, Stanford University Press, Stanford, 1988

25. Borch-Jakobsen, pp. 95, 163.

26. Borch-Jakobsen, p. 163

27. Anna Gibbs, 'Stalker: Affect Contagion, Mimetic Entrapment And Female Psychopathy', forthcoming.

28. Jennifer Biddle, 'Bruises That Won't Heal: Melancholic Identification and other Ethnographic Hauntings', Mortality, vol. 7, no. 1 2002, pp. 96-110

29. Moscovici, p. 273 and Rene Girard, To Double Business Bound: Essays on Literature, Mimesis, Anthropology, Johns Hopkins University Press, Baltimore, 1978.

30. Borch-Jkobsen, p. 145.

31. Ruth Leys, Trauma: A Genealogy, Chicago University Press, Chicago, 2000

32. The term 'corporeal unconscious' is used by Borch-Jacobsen, but it is also used by Rae Beth Gordon in a much more detailed analysis of the contribution of nineteenth-century pathologies and the psychophysiological theories that sought to explain them to performance styles in cabaret and early cinema. Rae Beth Gordon. Why the French Love Jerry Lewis: From Cabaret to Early Cinema, Stanford University Press, Stanford, 2001.

33. Michel Foucault, The Order of Things, Vintage Books, New York, 1973, p. 23.

34. Gibbs, 'Pauline Hanson'

35. Donald L. Nathanson, 'Affect, Affective Resonance and a New Theory for Hypnosis', Psychopathology, vol. 21, no. 2-3, 1988, pp. 126-37.

36. Gabriel Tarde, Etudes pénales et socials, 1892 , p. 343 , <http://www.uqac.ca/ Classiques_des_sciences_sociales/>

37. Maurizio Lazzarato, 'Postface' to Gabriel Tarde, Monadologie et Sociologie, Institut Synthélabo, Paris, 1999.

38. Gabriel Tarde, The Laws of Imitation, trans. Elsie Clews Parsons, Peter Smith, Gloucester, Mass., 1962, p. 193.

39. Tarde, The Laws of Imitation

40. See François Zourabichvili, 'Préface: Le Pouvoir en devenir: Tarde et l'actualité', in Gabriel Tarde, LesTransformations du pouvoir, Institut Synthélabo Paris, 2003, pp. 17-37.

41. Christian Borch, 'Urban Imitations: Tarde's Sociology Revisited', Theory, Culture \& Society, vol. 22, no. 3, 2005, pp. 81-100; see also Jaap van Ginneken, Crowds, Psychology and Politics 1871-1899, Cambridge University Press, Cambridge, 1992

42. Zourabichvili, pp. 21-2.

43. This, like the perception that imitation may be mutual, is absolutely consonant with René Girard's theory of mimetic desire. While Girard refers very little to Tarde, he clearly knows his work.

44. Gabriel Tarde, L'Opinion et la foule, Félix Alcan, Paris, 1901, p. 11.

45. Tarde, L'Opinion, p. 11.

46. Tarde, L'Opinion, pp. 5-6.

47. Tarde, L'Opinion, p. 6.

48. Tarde, L'Opinion, p. 212

49. Tarde, L'Opinion, p. 213.

50. Tarde, L'Opinion, p. 213, my translation.

51. Tarde, L'Opinion

52. Tarde, Transformations, p. 257

53. Michael Warner, Publics and Counterpublics, New York: Zone Books, 2002, p. 116.

54. Warner, p. 123.

55. Tarde, Transformations, p. 258

56. Tarde, Transformations, p. 259

57. Tarde, Lopinion, p. 21.

58. Virginia Nightingale, 'Are Media Cyborgs?', in Angel Gordo-Lopez and Ian Parker (eds), Cyberpsychology, Macmillan, London, 1999.

59. cf Ruth Leys, 'Mead's Voices: Imitation as Foundation, or, the Struggle against Mimesis', Critical Inquiry, vol. 19, no. 2, 1993.

pp. 277-307, 281. She is followed here by Borch, 'Urban Imitations'.

60. Lazzarato, p. 128 (my translation)

61. Lazzarato, p. 128 (my translation).

62. Manuel Castells, The Internet Galaxy: Reflections on the Internet, Business and Society, Oxford and New York, Oxford University Press, 2001.

63. See Julian Lee, 'Coming to an Inbox Near You', Sydney Morning Herald, 29-30 September 2007. p. 26.

64. Andrew Barry and Nigel Thrift, 'Gabriel Tarde Imitation, Invention and Economy', Economy and Society, vol. 36, no. 4, 2007, pp. 509-25.

65. Lazarsfeld. See, for example, the work of Paul.

66. Moscovici, p. 15.

67. Cited in Orr, p. 60.

68. Bernard Stiegler, 'The Disaffected Individual', working paper for the Ars Industrialis seminar, 'Suffering and Consumption', 25 February 2006, trans Patrick Crogan and Daniel Ross, August 2006.

69. Ron Burnett, 'Context, Technology,

Communication, and Learning', Educational Technology, vol. 42, no. 22, March-April 2002, pp. 67-70. 
70. See Alfred Gell, Art and Agency, Blackwell, Oxford, 1998.

71. William Condon, 'Neonatal Entrainment and Enculturation', in Margaret Bullowa (ed.), Before Speech: The Beginning of Interpersonal Communication, Cambridge University Press, Cambridge, 1979, pp. 141-8.

72. Lisa Blackman, 'Reinventing Psychological Matters: The Importance of the Suggestive Realm of Tarde's Ontology', Economy and Society, vol. 36, no. 4, 2007, pp. 574-96.

73. Lazzarato, p. 131

74. These are the loci of distraction identified by Margaret Morse, 'An Ontology of Everyday Distraction: The Freeway, The Mall and Television', in Patricia Mellencamp (ed.), Logics of Television. Indiana UP, Bloomington and Indianapolis, 1990, pp. 193-221.

75. Anna Gibbs, 'In Thrall: Affect Contagion and the Bio-Energetics of Media', M/C Journal, vol. 8, no. 6, 2005, <www.journal.media-culture.org.au/ 0512/10-gibbs.php>.

76. Julian Jaynes, The Origins of Consciousness in the Breakdown of the Bicameral Mind, Houghton Mifflin, Boston, 1976

77. Jaynes, p. 383

78. On mirror neurons, see, for example, Giacomo Rizzolatti and Laila Craighero, 'The Mirror Neuron System', Annual Review of Neuroscience, no. 27, 2004, pp. 169-92, and on neuropeptides see Candace Pert, Molecules of Emotion, Simon and Schuster, Sydney, 1998.

79. Léon Chertok and Isabelle Stengers, L'Hypnose: blessure narcissique, 1992; Nathanson.

80. Chertok and Stengers, p. 49.

81. Chertok and Stengers, p. 49

82. Jaynes, p. 385.

83. Merlin Donald, 'The Cenral Role of Culture in Cognitive Evolution: A Reflection on the Myth of the "Isolated Mind"', in Larry P. Nucci, Geoffrey B. Saxe and Elliot Turiel (eds), Culture, Thought and Development, Lawrence Erlbaum Associates, New Jersey, 2000, pp. 19-38.

84. Catherine Clément and Tobie Nathan, Le divan et le grigri, Odile Jacob, Paris, 1998

85. See, for example, Clément and Nathan, and Bronislaw Malinowski, Magic, Science and Religion and Other Essays, Doubleday and Co., New York, 1948.

86. See Gibbs, 'In Thrall'.

87. Brian Massumi, Parables of the Virtual, Duke University Press, Durham, 2005

88. Lazzarato, p. 112, my translation.
89. Jill Bennett, 'A Feeling of Insincerity: Politics, Ventriloquy and the Dialectics of Gesture', in Ernst van Alphen et al. (eds), The Rhetoric of Sincerity, Stanford University Press, Stanford, 1980.

90. Bourdieu, The Logic of Practice, trans. Richard Nice, Polity Press, Cambridge, 1992, p. 69

91. Bourdieu, p. 73. My thanks to Elspeth Probyn for drawing my attention to this particular formulation of Bourdieu's. She also discusses the larger passage in which it occurs in her book on shame (Blush: Faces of Shame, University of New South Wales Press, Sydney, 2005), and I would respond to her puzzlement there over Bourdieu's use of the term 'hallucinatory' in relation to emotion by suggesting that, although he doesn't explicitly cite him, Bourdieu clearly has Tarde's work in mind at this point: witness his reference to imitation ('mimesis', 'mimes') and action at a distance.

92. Brian Massumi, 'The Future Birth of the Affective Fact', Conference Proceedings: Genealogies of Biopolitics, p. 2, $<$ http://www.radicalempiricism org/biotextes/textes/massumi.pdf>

93. Stephan Lewandowsky, Werner G.K. Stritzke, Klaus Oberauer and Michael Morales, 'Memory for Fact, Fiction, and Misinformation: The Iraq War 2003', Psychological Science, vol. 16, no. 3, March 2005, pp. 190-5.

94. Lewandoswky, et al.

95. Emily Dunn, 'Getting High on Crowd Dynamics', Sydney Morning Herald, 28 January 2008, p. 18

96. It has been argued that physical crowds are now 'an icon that circulates within, a political economy characterised by the coexistence of media aggregation and bodily disaggregation'. Jeffrey T. Schnapp and Matthew Tiews, 'Introduction: A Book of Crowds', in Jeffrey T Schnapp and Matthew Tiew (eds), Crowds, Stanford University Press, Stanford, 2006 p. xi.

97. Isabelle Stengers, 'Introductory Notes On An Ecology of Practices', Cultural Studies Review, vol. 11, no. 1, March 2005, pp. 183-96.

98. Stengers, 'Introductory Notes'.

99. Alfred Gell, 'Technology and Magic', Anthropology Today, vol. 4, no. 2, April 1988, pp. 6-9.

100. Gell, p. 8 